\title{
NEWS FROM THE DEPARTMENTS
}

University of Alberta. Professor E. S. Keeping, who retired as Head of the Department in September 1961, has been appointed a Visiting Professor at the University of Oklahoma for 1962-63.

The following new appointments have been made in Edmonton:

Dr. A. E. Livingston, as Associate Professor, from Montana State University (in analysis).

Dr. R. L. M=Kinney, as Assistant Professor, from the University of California, Riverside (in topology).

Mr. R. J. Tait, as Assistant Professor, from the University of Gla sgow, Scotland (in applied mathematics).

Mr. D. W. Willett, as Assistant Professor, from the California Institute of Technology (in applied mathematics).

The following have been appointed in Calgary:

Dr. S. C. Das, as Assistant Professor, from the India Institute of Technology, Madras (in applied mathematics).

Dr. A. Sharma, as Associate Professor, from Harvard University (in analysis).

The degree of Ph. D. in mathematics has been awarded to Mr. J.W. Moon for a thesis on graph theory. He has been awarded an N.R.C. post-doctoral fellowship to work at University College, London.

Mr. R. L. Forbes has received the M. Sc. degree in mathematics for a thesis on the Gibbs phenomenon in Fourier series. He has been appointed a Sessional Lecturer in Calgary.

Professor F. Harary, of the University of Michigan, spoke to the Mathematics Colloquium in April on Structure in Organizations.

\section{Assumption University of Windsor.}

New Appointments: Dr. C. Kassimatis as Associate Professor, Mr. Lucio Artiaga as Lecturer.

Promotions: Dr. Lorne Campbell has been promoted to Associate Professor. 
Leave of Absence: Dr. T. Klemola - to attend the Institute for Advanced Study at Princeton, N.J.

Mr. W. Zayachkoviski - to do graduate work at Michigan State University.

Dr. Hermes Eliopoulos - is spending the summer studying with Professor Lichnerowicz at the College de France prior to attending the International Mathematical Congress in Stockholm.

University of British Columbia. Mr. Richard A. Cleveland has been appointed to an Assistant Professorship as of July 1, 1962.

Mrs. Sandra B. Cleveland has been appointed to a Lectureship as of July 1, 1962. $1961-62$ :

University of Ottawa. The following seminars were held in

Topics in geometry --Helfenstein

Homological methods in theory of modules --Kleisli

Statistical methods in computation --Howland

Lectures on "Bourbaki method" by Linis, Kleisli and Lightstone (Carleton).

Guest Lecturers: Johnson (Rochester); Lorentz (Sy racuse);

Neumann (Manchester and N.Y.U.); Robinson, P. Scherk and A. Sherk (Toronto); Rattray and Riehm (McGill); Maranda (Montreal).

\section{Queen's University.}

New Appointments:

Dr. Paulo Ribenboim (algebra)

Mr. D. H. Crawford (mathematics education)

Mr. I. Z. Bouwer, from South Africa and recently from Delft (algebra).

A new book on Grade 9 mathematics, written by Professor A.J. Coleman in collaboration with three Ontario high school teachers, is to appear early this summer. All royalties from sales in Ontario have been assigned by the authors to a fund for the advancement of mathematics in the Province. 